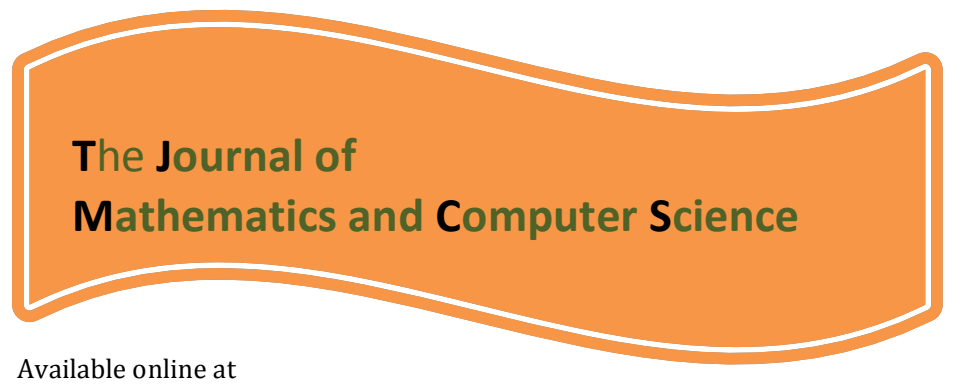

http://www.TIMCS.com

The Journal of Mathematics and Computer Science Vol. 4 No.2 (2012) 270 - 277

\title{
Main Categories of Information Technologies Systems Regarding Process Orientation and Knowledge Orientation
}

\author{
Emad Farazmand ${ }^{* 1}$, Mahdi Sayyadi2 \\ ${ }^{1}$ Department of Computer Engineering, Islamic Azad University, Mahshahr Branch, Mahshahr, Iran, \\ e.farazmand @gmail.com \\ ${ }^{2}$ Department of Computer Engineering, Islamic Azad University, Mahshahr Branch, Mahshahr, Iran \\ Sayyadi.mahdi @gmail.com
}

Received: January 2012, Revised: April 2012

Online Publication: June 2012

\begin{abstract}
Information Technology is one the most important resources in today's business environment and successful businesses are investing heavily in IT. In fact in today's business environment it is impossible to manage an organization without using IT tools and systems. Success of IT systems in an organization depends on many factors that one of them is fitness of used system with organizational working model. We can identify organizational working model by considering two dimensions: level of interdependency and the level of the complexity in work. In parallel with these two dimensions we can introduce two dimensions about IT systems that Used in the organization: business process orientation and knowledge orientation. Doing so, in this paper four categories of IT systems and tools have been identified that each one is proper for specific organizational working model. So this model could be useful to recognize proper type of IT systems for specific organization based on its working model.
\end{abstract}

Keywords: Organizational working model, IT systems, Process orientation and knowledge orientation

\footnotetext{
${ }^{*}$ Corresponding Author
} 


\section{INTRODUCTION}

Information Technology is one the most important resources in today's business environment and successful businesses are investing heavily in IT. [4]. In fact in today's business environment it is impossible to manage an organization without using IT tools and systems.

Experiences show that whenever businesses use IT system that is fit with their organizational structure and working model and also organizational culture, they will become successful in the way of their business and if else they will fail. So before using IT systems in organization at first it is important to know organizational working models that are the nature of work in an organization or different departments.

According to [2] we can consider two dimensions to model the organization: level of interdependence involved - that is the degree to which individuals and organizations need to collaborate and interact and complexity of work involved - the degree to which employees need to apply their judgment and interpret a variety of information. Based on these two dimensions Accenture institution has identified four distinct categories of works, or "Work Model".(fig. 1)

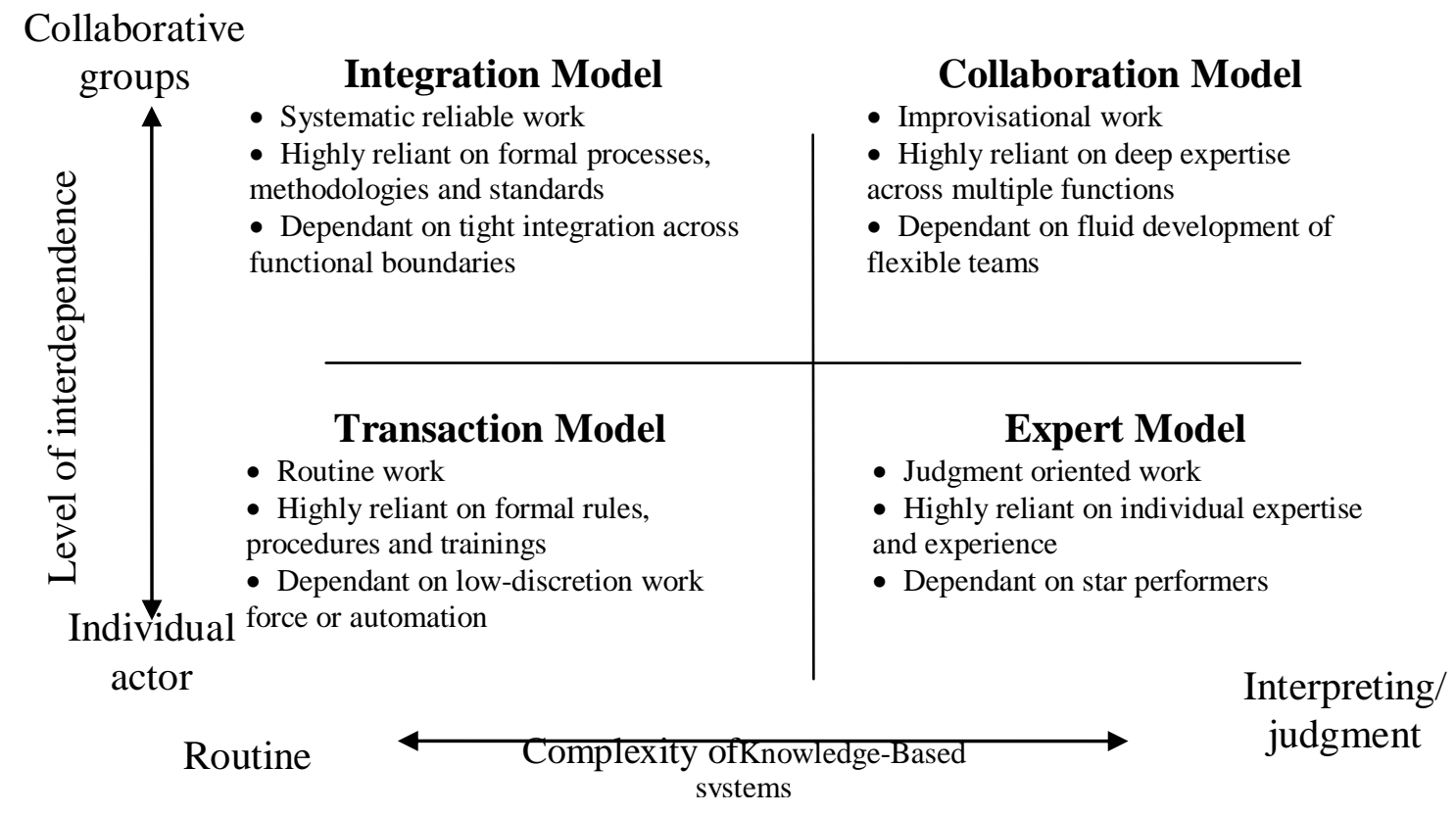

Fige. 1- organizational working model

- Transaction mode, in which there is a low degree of both interdependence and complexity. Work is typically routine, highly reliant on formal rules, procedures and training and depends on a workforce that exercises little discretion. 
-Integration model, in which there is a high degree of interdependence and low degree of complexity. Work is systematic and repeatable, relies on formal processes, methodologies and standards, and depends on tight integration across functional boundaries.

-Expert model, in which there is low interdependence and high complexity. Work requires judgment and is dependent on "star performer".

- Collaboration model, in which there is a high degree of both interdependence and complexity. Work involves improvisation and learning by doing, and relies on deep expertise across functions and the use of flexible teams.

Considering these organizational working models, we want to introduce a framework for categorizing IT tools and systems in organization. To do so we consider two factors that are business process orientation (that supports work interdependency) and knowledge involved in the system (that support work complexity).

\section{Business Process Orientation}

During the 1980s, Michael Porter introduced the concepts of interoperability across the value chain and horizontal organization as major strategic issues within firm. Edvard Demon developed the "Deming Flow Diagram" depicting the horizontal connections across a firm, from the customer to the supplier, as a process that could be measured and improved like any other process In 1990 two researchers, Thomas Davenport and James Short, proposed that the process orientation in an organization was a key component of success. In 1993, Michael Hammer who led the "reengineering" craze of the 1990s, also presented Business Process Orientation concept as an essential ingredient of a successful reengineering effort.

Hammer described the development of a customer-focused, strategic business processbased organization enable by rethinking the assumptions in a process-oriented way and utilizing information technology as a key enabler[7].

As is clear from literature, the process orientation is most consideration for management Scientifics in recent years. In fact the more reliable and customer oriented form of organizations is process oriented organization rather than functional organizations [7]. To support the processes of such an organization (process oriented organization) there should be systems that support organizational processes. When we are talking about process we should consider several organizational units and between functional communications and coordination.

In functional organizations there is often an application program that supports the functions of specific department. An application program is a computer program designed to support a specific task or a business process (such as execute the payroll) or, in some 
cases, another application program. [9] The application program usually involved a database that contains data related to regarded department and isn't share with another departments of the organization and also its database haven't any relationship with other databases all over the organization.

If there is process-oriented organization, we need between departmental systems and some times in which the process goes on out of the organization boundaries we need between organizational systems to support the processes. While an application program is usually related to a functional area, other information systems serve several departments or the entire enterprise. These information systems together with the departmental applications comprise the enterprise wide information system (EIS). One of the most popular enterprise applications is enterprise resource planning (ERP), which enables companies to plan and manage the resources of an entire enterprise. ERP systems present a relatively new model of enterprise wide computing [9].

Some information systems connect two or more organizations. They are referred to as inter-organizational information systems (IOSs). Inter-organizational information systems play a major role in e-commerce, as well as in supply chain management support[9]

Based on business process orientation we can construct a continuum about IT tools and systems with two extremes like fig.2.

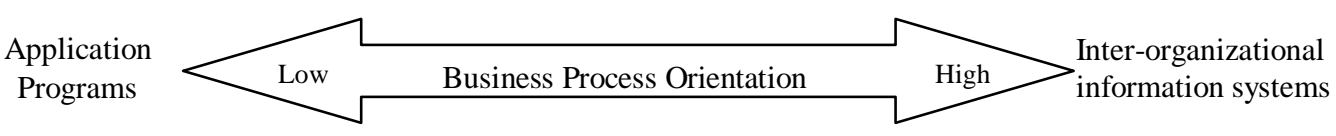

Fig. 2. Business process orientation and IT systems

\section{Knowledge Orientation in IT Systems}

The level of productivity, or the success of management, depends on the performance of managerial functions such as planning, organizing, directing and controlling. To carry out this functions managers are engage in continues process of making decisions. [10]. The environment in which organizations operate today is changing very rapidly and the nature of decision making became very complex and difficult not only for management but also for employees all over the organization (level of complexity is related to the nature of organizational working model).

Employees and managers to make decision not only need to have qualified and accurate data and information, but also should have required knowledge to analyze regarded information in the way of decision improvement. Let us to have glance on data, information and knowledge in organization according to [9]: 
Data items refer to an elementary description of things, events, activities, and transactions that are recorded, classified, and stored, but not organized to convey any specific meeting. Data items can be numeric, alphanumeric, figures, sounds, or images. A student grade in a class is a data item, and so is the number of hours an employee worked in a certain week. A database consists of stored data items organized for retrieval.

Information is data that have been organized so that they have meaning and value to the recipient. For example, a student's grade point average is information. The recipient interprets the meaning and draws conclusions and implications from the data. Data items typically are processed into information by means of an application. Such processing represents a more specific use and a higher value-added than simple retrieval and summarization from a database. The application might be a Web-based inventory management system, a university online registration system, or an Internet-based buying and selling system.

Finally, knowledge consists of data and/or information that have been organized and processed to convey understanding, experience, accumulated learning, and expertise as they apply to a current problem or activity. Data that are processed to extract critical implications and to reflect past experiences and expertise provide the recipient with organizational knowledge, which has a very high potential value. Currently, knowledge management is one of the hottest topics in the IT field.

So in an organization, based on organizational working model there may be systems that use data or the systems that use knowledge to support decision- making.

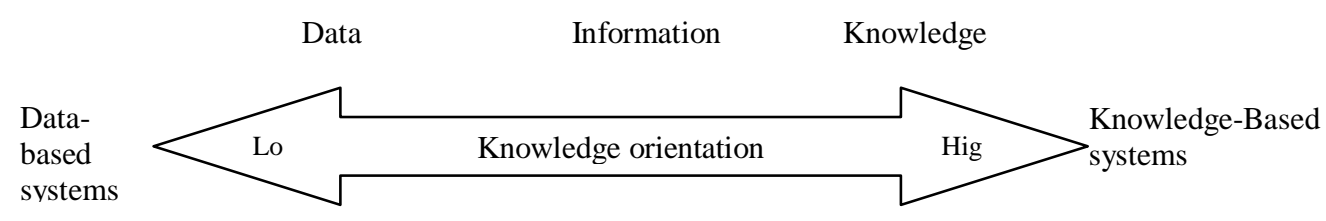

Figure 3. Knowledge orientation and IT systems

Data-based systems are systems that can capture organizational transactions and perform routine jobs in organization. These systems fall in the category of Online Transaction Processing (OLTP) systems. OLTP involves gathering input information, processing that information and updating existing information to reflect the gathered and processed information[4].

In some cases there should be an IT based system to support decision-making and solving problems in the organization. Knowledge base systems are most qualified systems for such a circumstance. Also there may be several sources of knowledge in an organization like human knowledge, organizational documents, and organizational best practices and so on. 
Facing a knowledge economy [8] and knowledge based competition [3] an organization should be able to secure various types of knowledge assets and maximize their strategic value. To do this, many organizations began to reexamine and rearrange their business strategies, processes, information technologies, and organizational structure from a knowledge perspective [1]. Adoption and assimilation of the knowledge management paradigm requires the design and establishment of structures, processes, and technologies along with organizational knowledge resources [5].

So it is clear that when decision-making in organization becomes more complex and the value of knowledge increases, we will need IT systems that have a knowledge base in core and let Users to access to the required knowledge in useful manner. This knowledge based systems also fall in the category of Online Analytical Processing (OLAP) systems. OLAP is manipulation of information to support decision-making.

Based on knowledge orientation of IT systems we can build a continuum as figure 3 .

\section{A framework for categorizing Information Technology systems}

Considering two discussed dimensions, process orientation and knowledge orientation of the system, we can identify four main areas about Information Technology systems fig. 4 This framework is conceptual and helps to identify information technology systems that are more proper for regarded organization in the base of organizational work model. Let us to have more discussion about these four main areas:

1. Island Transactional Systems: this area is related to the systems that facilitate specific functions in organization that aren't complex and have routine and structured procedures.

The main part of these systems is their database module and some times they are not more than a database that works with simple procedures. Capturing and retrieving data and information related to operational transactions in specific department or function is the expected feature of systems in this area. Examples of these systems are application programs and specific function systems such as accounting system, financial system or inventory system.

2.Integrating Systems: These systems are used to integrate different parts of an organization and sometimes result in inter-organizational integration based on improved business processes rather than organizational functions. Data in this kind of systems is shared data within organization and sometimes between organizations with defined level of access for different departments. Examples from this category are ERP, CRM and SCM systems that result in integration between several participants in a business process.

3. Island Analytical Systems: this category describes systems that contain knowledge required to solve problems in specific area or knowledge about specific expertise and support users to solve regarded problem by offering useful solutions. These systems have a 
knowledge base that extracted from experts mind and are a kind of OLAP systems. Also these systems may feed by organizational data and use several models to analyze decision making situation and offer solutions to user. Expert Systems and Decision Support Systems are examples of this category.

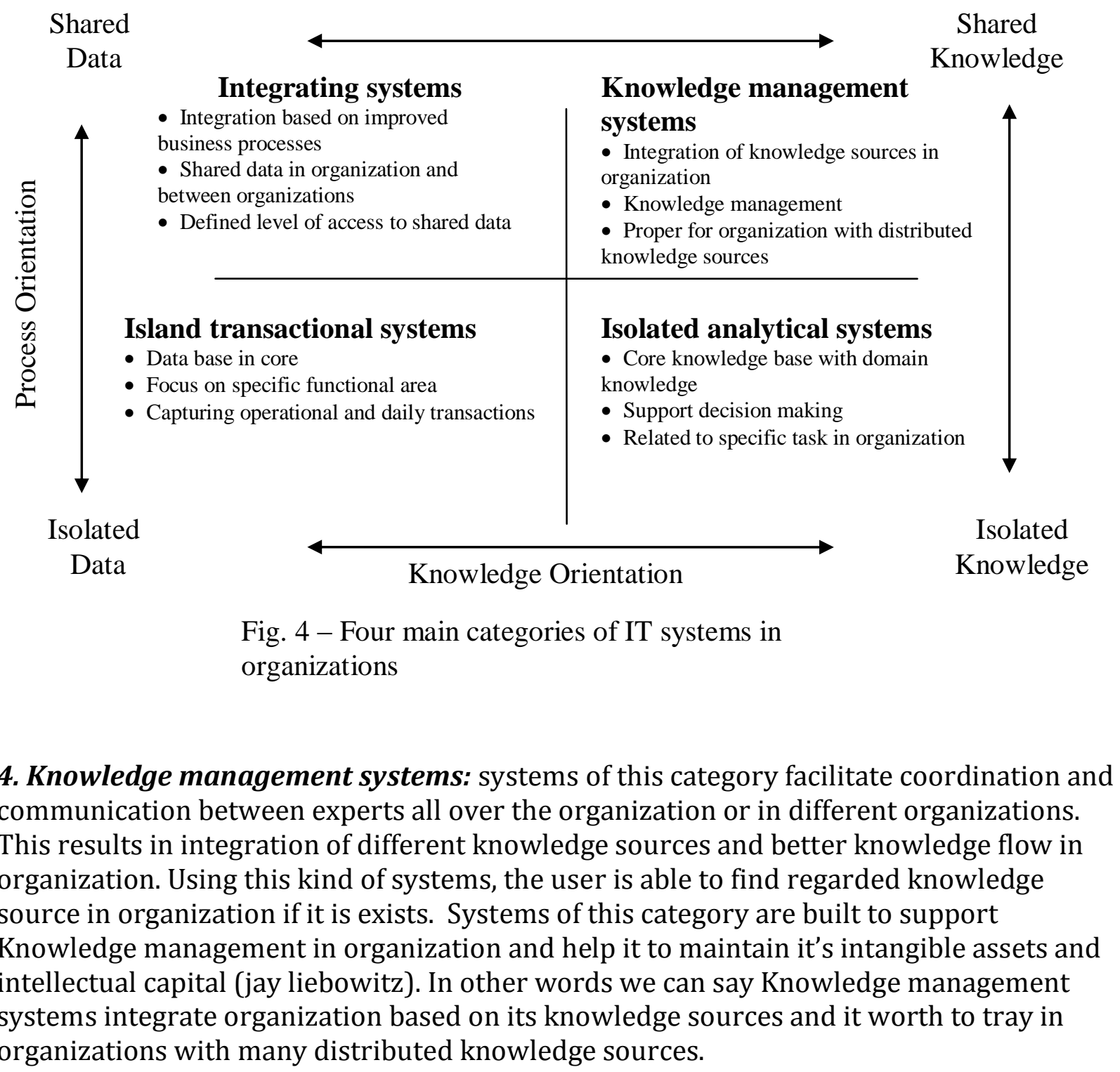

\section{Conclusion}

In this paper we reviewed the organizational working models and then discussed about different categories of IT systems and tools based on two dimensions, process orientation and knowledge orientation. This results in four main categories of IT systems. Each 
category we recognized is best fitted for specific working model. For example integrating systems are more proper to use in integration model. Using this model makes it clear that which kinds of IT systems are proper for different organizations and different departments of organization regarding their working model.

In fact in this paper we want to say that the IT systems should be related to organizational working model. For future works we can add organizational level to this model and study the impact of organizational level on usage of different categories of IT systems.

\section{REFERENCE}

[1]- Davenport, T. H., Jarvenpaa, S. L., Beers, M. C.," Improving Knowledge Work Processes" Slon Management Review, 37(4), 53-55, 1996.

[2]- Donoghue. L. P., Harris. J. G., Weitzman. B. A., "Knowledge Management Strategies that Creates Value” Outlook, NO. 1, 1999.

[3]- Drucker, P. F., "The Post Capitalist Society" Oxford, Butterworth- Heinemann, 1993.

[4]- Haag. s., Cammings. M., McCubbrey. D. J., "Management Information Systems For the Information Age" McGraw-Hill, Third Edition, New York, 2002.

[5]- Lee, J. H., Kim, Y. G., "A Stage Model Of Organizational Knowledge Management : a Latent Content Analysis." Expert Systems With Applications, 20(4), 299-311, 2001.

[6]- Liebowitz. J., "Knowledge Management, Learning from Knowledge engineering", CRC Press, USA, 2001.

[7]- McCormack. K.P., Johnson. W.C., Walker. W.T., "Supply Chain Networks and Business Process Orientation, Advanced Strategies and Best Practices”, ST. Lucie Press, USA, 2003.

[8]- Nonaka, I. "A Dynamic Theory of Organizational Knowledge Creation", Organization Science, 5(1), 38-50, 1994.

[9]- Turban, Efraim; Mclean, Ephraim; Wetherbe; "Information Technology for management", John Wiley \& Son, inc 2002.

[10]- Turban. E., Aronson. J. E., “Decision Support System And Intelligent Systems”, Prentice-Hall, India, Sixth Edition, New Delhi, 2003. 